\title{
Mortality and cerebral metabolism after bilateral carotid artery ligation in normotensive and spontaneously hypertensive rats
}

\author{
M. FUJISHIMA ${ }^{1}$, J. OGATA, T. SUGI, AND T. OMAE \\ From the Second Department of Internal Medicine, \\ The Faculty of Medicine, Kyushu University, Fukuoka, Japan
}

SYNOPSIS Mortality and cerebral glycolytic metabolism were studied after bilateral ligation of the common carotid artery in normotensive Wistar rats (NTR), and spontaneously hypertensive rats (SHR) derived from Wistar strain. In the first 24 hours after occlusion of carotid arteries, $72 \%$ of 108 SHR died, whereas it was fatal in only $16 \%$ of 43 NTR. In SHR, cerebral lactate and cerebral lactate/pyruvate ratio (L/P ratio) increased by 12.4 and 12.1 times the control, respectively at five to six hours after ligation, and remained raised even in rats surviving for two to three days thereafter. Changes in cerebral lactate and L/P ratio were minimal in NTR. Cerebral ATP decreased markedly at five to six hours after ligation in SHR studied. These results indicate that bilateral carotid artery ligation causes severe brain damage in SHR but not in NTR, suggesting hypertension per se to be operative for the development of cerebral ischaemia.

In Wistar rats, it is difficult to cause a consistent ischaemic damage of the brain by bilateral ligation of the common carotid artery only (Payan et al., 1965), but it is possible to induce ischaemic anoxic lesions by a combination of unilateral carotid ligation and anoxic exposure (Levine, 1960; Plum et al., 1963). A similar study has not been made in spontaneously hypertensive rats (SHR), derived from the Wistar strain by Okamoto and Aoki (1963).

The present study was undertaken to determine mortality and chronological changes in cerebral glycolytic metabolism after bilateral ligation of the carotid artery in SHR and in normotensive Wistar rats (NTR) as a control group.

\section{METHOD}

MORTALITY One hundred and eight SHR and 43 NTR males, weighing between 200 and $450 \mathrm{~g}$, aged from 4 to 9 months, were anaesthetized with intra-

1 Address for correspondence: The Second Department of Internal Medicine, The Faculty of Medicine, Kyushu University, Maidashi 3-1-1, Higashi-ku, Fukuoka City 812, Japan.

(Accepted 14 October 1975.) peritoneal amylobarbitone $(10 \mathrm{mg} / 100 \mathrm{~g}$ of body weight). Both common carotid arteries were exposed through ventral midline cervical incisions, separated from the vagosympathetic trunks, and doubly ligated at the same time. After the skin incision was closed with silk sutures, the animals were returned to their cages and were observed for the development of neurological deficits in the form of abnormal circling movements or rolling seizures. Mortality was recorded at 24 hours, and daily to seven days after ligations.

ARTERIAL ACID-BASE BALANCE AND CEREBRAL METABOLISM In 22 SHR and 21 NTR, arterial acidbase balance, arterial blood pressure, and cerebral lactate and pyruvate concentrations were determined before, five to six hours, and two to three days after bilateral ligation of the carotid artery. In each ligated rat, reanaesthetized with amylobarbitone before being killed, one femoral artery was cannulated for blood pressure recording with an electromanometer, and also for anaerobic sampling for blood gas analysis. Arterial $\mathrm{pO}_{2}, \mathrm{pCO}_{2}$, and $\mathrm{pH}$ were determined by an IL meter model 113 .

A plastic funnel was fitted into a skin incision over the skull bone and the head was frozen in liquid nitrogen in situ. The entire supratentorial portion of 
the brain was chiselled out in the frozen state. In rapid sequence, frozen brain was weighed and ground after the addition of cold perchloric acid. The tissue homogenate, maintained at $0^{\circ}$ to $4^{\circ} \mathrm{C}$, was centrifuged and neutralized with potassium hydroxide at $\mathrm{pH}$ between 4.5 and 5.0. Lactate and pyruvate concentrations in the tissue homogenates, and ATP concentration in some rats, were determined by the standard enzymatic methods.

\section{RESULTS}

MORTALITY Early mortality, within the first 24 hours, after bilateral ligation of the common carotid artery in SHR and in NTR is shown in Table 1. The animals were divided into two groups by body weight, one between 200 and $300 \mathrm{~g}$, and the other over $300 \mathrm{~g}$ of body weight.

\section{TABLE 1}

EARLY MORTALITY AFTER BILATERAL CAROTID ARTERY LIGATION IN NORMOTENSIVE AND SPONTANEOUSLY HYPERTENSIVE RATS

\begin{tabular}{cccc}
\hline & \multirow{2}{*}{$\begin{array}{c}\text { Body weight } \\
(\mathrm{g})\end{array}$} & \multicolumn{2}{c}{ Died within 24 hours } \\
\cline { 3 - 4 } & & $($ no. $)$ & $(\%)$ \\
\hline SHR & $200-300$ & $45 / 62$ & 73 \\
& over 300 & $33 / 46$ & 72 \\
\hline Total & & $78 / 108$ & 72 \\
\hline NTR & $200-300$ & $3 / 27$ & 11 \\
& over 300 & $4 / 16$ & 25 \\
\hline Total & & $7 / 43$ & 16 \\
\hline
\end{tabular}

SHR: spontaneously hypertensive rat. NTR: normotensive rat.

The body weight of $300 \mathrm{~g}$ is comparable with the age of 25 to 30 weeks in both SHR and NTR. In SHR, $73 \%$ of 62 rats weighing between 200 and $300 \mathrm{~g}$, and $72 \%$ of 46 rats weighing over $300 \mathrm{~g}$ died within 24 hours after ligation, whereas, in NTR, $11 \%$ of 27 rats and $25 \%$ of 16 rats, respectively, died during the first 24 hours. The survival rate at seven days after ligation was $19 \%$ in SHR, and $79 \%$ in NTR. Total mortality was, therefore, significantly higher by 4.5 times in SHR than in NTR.

Death of spontaneously hypertensive rats most frequently occurred within 12 hours after liga-

\section{TABLE 2}

MEAN ARTERIAL PRESSURE, ARTERIAL pH, $\mathrm{pCO}_{2}$, AND $\mathrm{pO}_{2}$ IN NORMOTENSIVE AND SPONTANEOUSLY HYPERTENSIVE RATS AFTER BILATERAL CAROTID ARTERY LIGATION

\begin{tabular}{lccc}
\hline & \multicolumn{3}{c}{ Bilateral carotid ligation } \\
\cline { 2 - 4 } & Before & $5-6$ hours & $2-3$ days \\
\hline SHR (no.) & 9 & 7 & 6 \\
MAP (mmHg) & $159 \pm 6$ & $105 \pm 23$ & $146 \pm 9$ \\
pH & $7.428 \pm 0.010$ & $7.389 \pm 0.056$ & $7.413 \pm 0.022$ \\
pCO $(m m H g)$ & $39.0 \pm 1.3$ & $43.0 \pm 5.6$ & $38.2 \pm 1.4$ \\
pO $(m m H g)$ & $89.6 \pm 6.7$ & $85.7 \pm 7.4$ & $83.4 \pm 2.8$ \\
& & & \\
$\mathrm{NTR}_{2}(\mathrm{no})$. & 8 & 4 & 9 \\
$\mathrm{MAP}(\mathrm{mmHg})$ & $118 \pm 6$ & $148 \pm 6$ & $114 \pm 6$ \\
pH & $7.397 \pm 0.022$ & $7.479 \pm 0.020$ & $7.420 \pm 0.008$ \\
pCO $(\mathrm{mmHg})$ & $40.9 \pm 1.4$ & $36.3 \pm 2.5$ & $39.0 \pm 1.5$ \\
pO $_{2}(\mathrm{mmHg})$ & $84.2 \pm 4.5$ & $90.1 \pm 8.1$ & $84.8 \pm 3.3$ \\
\hline
\end{tabular}

Values are mean \pm SEM.

tion. In these rats, circling behaviour or paucity of movement on one or both sides of the body was frequently observed. Furthermore, unilateral or bilateral ptosis of the eye was common. Most SHR started to hyperventilate immediately after ligation and this lasted for a few hours. Before death, they became obtunded or comatose, and lay motionless. In rare rats, convulsive seizure, severe irritability, or abnormal agitated motion was observed during a short period before death.

ARTERIAL ACID-BASE BALANCE AND CEREBRAL METABOLISM Table 2 shows mean values for mean arterial blood pressure and acid-base parameters. Arterial pH in SHR was 7.428 before, 7.389 at five to six hours after carotid ligation, and 7.413 at two to three days later. Arterial $\mathrm{pCO}_{2}$ was $39.0 \mathrm{mmHg}$ before, and slightly increased to $43.0 \mathrm{mmHg}$ at five to six hours after ligation. At two to three days, it was $38.2 \mathrm{mmHg}$. Arterial $\mathrm{pO}_{2}$ did not differ in the three stages. In NTR, arterial acid-base balance changed in a similar manner to that in SHR at the various time intervals, except for a slight rise in $\mathrm{pH}$ with a concomitant decrease in $\mathrm{pCO}_{2}$ at five to six hours after occlusion.

Lactate and pyruvate concentrations, and lactate/pyruvate ratio ( $\mathrm{L} / \mathrm{P}$ ratio) of the brain tissue before, five to six hours and two to three days after ligation are summarized in Table 3 . In seven SHR, cerebral lactate increased from an 
TABLE 3

LACTATE AND PYRUVATE CONCENTRATIONS, AND LACTATE/ PYRUVATE RATIO IN BRAIN TISSUE OF NORMOTENSIVE AND SPONTANEOUSLY HYPERTENSIVE RATS AFTER BILATERAL LIGATION OF CAROTID ARTERY

\begin{tabular}{cccc}
\hline & \multicolumn{3}{c}{ Bilateral carotid ligation } \\
\cline { 2 - 4 } & Before & $5-6$ hours & $2-3$ days \\
\hline $\begin{array}{c}\text { SHR (no.) } \\
\text { Lactate } \\
\text { (mmol/kg) }\end{array}$ & 9 & 7 & 6 \\
$\begin{array}{c}\text { Pyruvate } \\
\text { (mmol/kg) }\end{array}$ & $1.76 \pm 0.11$ & $21.58 \pm 4.06$ & $9.75 \pm 2.16$ \\
L/P ratio & $15.2 \pm 1.7$ & $162.0 \pm 36.8$ & $40.5 \pm 11.7$ \\
$\begin{array}{c}\text { NTR (no.) } \\
\text { Lactate } \\
\text { (mmol/kg) }\end{array}$ & $1.49 \pm 0.08$ & $2.24 \pm 0.65$ & $1.76 \pm 0.21$ \\
$\begin{array}{c}\text { Pyruvate } \\
\text { (mmol/kg) }\end{array}$ & $0.123 \pm 0.010$ & $0.147 \pm 0.022$ & $0.120 \pm 0.005$ \\
L/P ratio & $12.7 \pm 0.9$ & $14.9 \pm 2.2$ & $15.0 \pm 1.8$ \\
\hline
\end{tabular}

Values are mean \pm SEM. $L / P$ ratio: lactate/pyruvate ratio.

average control value of $1.76 \mathrm{mmol} / \mathrm{kg}$ to 21.58 $\mathrm{mmol} / \mathrm{kg}(1243 \%)$, at five to six hours after ligation, and in five of those the value exceeded $20 \mathrm{mmol} / \mathrm{kg}$ (Figure, left). Cerebral lactate remained elevated in six SHR which survived for two days or more, and its mean value was 9.75 $\mathrm{mmol} / \mathrm{kg}\left(554^{\circ} \%\right)$. Two rats of these six SHR had a higher level of lactate than $10 \mathrm{mmol} / \mathrm{kg}$ but less than $20 \mathrm{mmol} / \mathrm{kg}$.

In a similar manner, cerebral $L / P$ ratio increased from the control value of 15.2 to the maximum level of $162.0(1209 \%)$ at five to six hours, and then slightly decreased to 40.5 $(302 \%)$ at two to three days after ligation, but its value was significantly higher than that before ligation (Figure, right).

On the other hand, in NTR, either cerebral lactate or L/P ratio increased to much less extent than in SHR after ligation. At five to six hours interval from ligation, cerebral lactate in NTR was $2.24 \mathrm{mmol} / \mathrm{kg}(150 \%)$, of the preligating control value. Of nine NTR which survived for two days or more, cerebral lactate was normal in eight and rose slightly in one, and its mean value was not different from the preligating value.

Cerebral ATP was determined in a total of 11 SHR. A mean value of ATP was $2.07 \mathrm{mmol} / \mathrm{kg}$ in four rats before ligation, $0.74 \mathrm{mmol} / \mathrm{kg}(36 \%)$ in five rats with five to six hours' interval after ligation, and $1.73 \mathrm{mmol} / \mathrm{kg}$ in two rats which

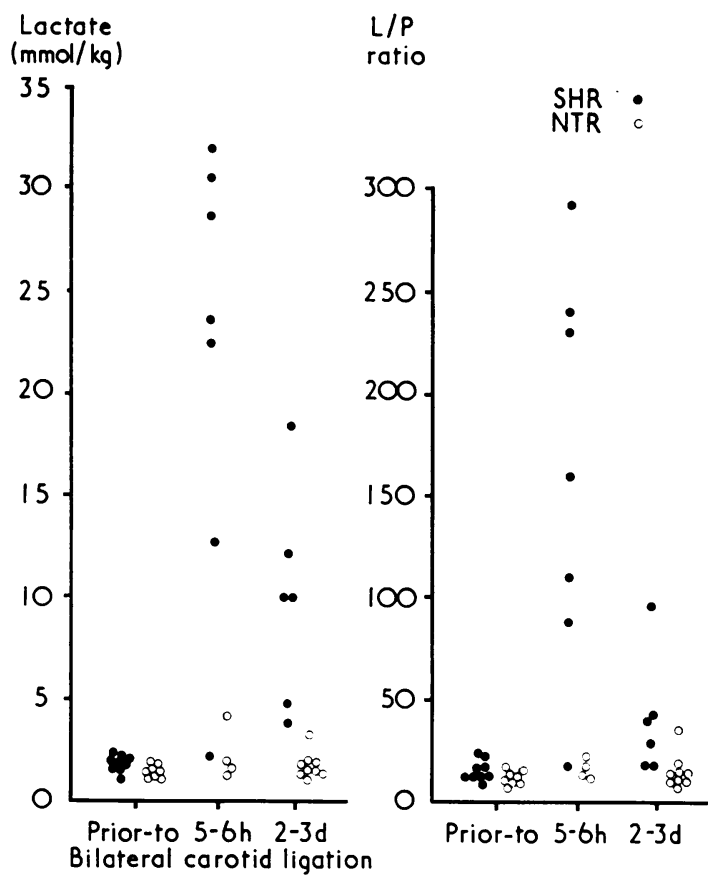

FIGURE Cerebral lactate (left) and lactate/pyruvate ratio (right) at various time intervals from bilateral ligation of carotid artery in normotensive rats $(O)$ and spontaneously hypertensive rats $(\bigcirc)$.

survived for two to three days. In one of five SHR with five to six hours' interval, ATP decreased pronouncedly to $0.13 \mathrm{mmol} / \mathrm{kg}$ or only $6.3 \%$ of the control, although cerebral lactate in this rat increased markedly to $28.25 \mathrm{mmol} / \mathrm{kg}$, or 16 times the control. On the other hand, one of these rats had a normal ATP value of $1.93 \mathrm{mmol} / \mathrm{kg}$, accompanied with a minimal increase in cerebral lactate of $2.09 \mathrm{mmol} / \mathrm{kg}$, or only by $18 \%$ increase. These results indicate an inverse correlation between ATP and lactate, a greater increase in cerebral lactate being accompanied by a more marked decrease in cerebral ATP.

\section{DISCUSSION}

From the present study, it is apparent that bilateral carotid ligation caused severe and fatal damage of the brain in SHR, but not in NTR. Early mortality in SHR was 4.5 times higher than in NTR, and most deaths in SHR occurred 
within 12 hours after ligation. Metabolic study suggests a cause for such a high mortality rate in SHR.

Mortality in various strains of rats has been studied by many investigators after bilateral occlusion of the carotid artery, or unilateral ligation associated with anoxic exposure, known as Levine's procedure. They have demonstrated marked strain differences in response to carotid ligation. Payan et al. (1965) reported that early mortality of rats after a simultaneous ligation of both carotid arteries under ether anaesthesia varied from nil in the Lewis strain to $100 \%$ in the $\mathrm{AC1}, \mathrm{F} 344$, and CDF strains, although no anatomical differences of their cerebral vasculatures have been described. One of $10(10 \%)$ Wistar rats, died within 24 hours after bilateral ligation in their study, which is compatible with our results showing a mortality of $16 \%$ in NTR. Plum et al. (1963) observed that 10 of $27(37 \%)$ male Sprague-Dawley rats died within 24 hours after an anoxic-ischaemic procedure-namely, prior ligation of the unilateral carotid artery and maintenance at inspired $\mathrm{pO}_{2}$ of $30-35 \mathrm{mmHg}$ for 30 minutes.

It has been recently demonstrated that unilateral hemispheric infarction can be produced in the mongolian gerbil (Merionus unguiculatus) by ligation of the ipsilateral common carotid artery. This unique characteristic of the gerbil is due to an absence of connecting arteries between the basilar and the carotid systems, or to the presence of an incomplete circle of Willis. Levine and Sohn (1969) have described that seven of 39 $(18 \%)$ infantile gerbils, died within the first 24 hours after right common carotid ligation under ether anaesthesia. Kahn (1972) reported that four of 30 mature gerbils $(13 \%)$ died within 24 hours, and all 16 deaths $(53 \%)$ occurred during the five days after left common carotid ligation under pentobarbitone anaesthesia. Similarly, Harrison and Russell (1972) observed in adult gerbils of either sex that right carotid occlusion caused death of 10 of $26(38 \%)$ rats in the first 24 hours and $17(65 \%)$ during the five days thereafter. On the other hand, bilateral ligation of the carotid artery in mature male gerbils caused death in all (Levine and Payan, 1966).

Contrary to the common concept of absence of the posterior communicating artery, Levy and Brierley (1974) recently reported that, even in the gerbils with occluded carotid artery, coloured dye injected into the aorta appeared in the cerebellum and also in the cerebrum, although the filling time in the latter was delayed by at least 30 seconds. They concluded that anatomical communications exist between the carotid and the basilar systems even in gerbils. However, such a delayed appearance of the injected dye in the cerebrum after carotid ligation may suggest that cerebral circulation to the carotid territory was markedly reduced to cause ischaemic changes in these rats. The functional communication between these two systems seems to be inadequate or absent despite the existence of anatomical connections.

In contrast with the low mortality of NTR, there was an extremely high death rate in SHR after bilateral carotid ligation. These results suggest that the collateral circulation is not sufficient to feed the carotid flow areas through the posterior communicating arteries, which might be lacking or incomplete as in gerbils, but in SHR; this is not the case. Our previous study (Ogata et al., 1976) showed that the distribution of cerebral arteries and the ratio of the posterior communicating artery to the basilar artery are essentially the same in both NTR and SHR. In the latter the diameter of cerebral arteries is somewhat smaller than in NTR. Furthermore, morphological changes in cerebrovascular walls secondary to persistent hypertension are not observed even in SHR.

Cerebral lactate in SHR is increased to an extreme extent at one hour after bilateral carotid ligation (Fujishima et al., 1975a) and is maximal five to six hours later as demonstrated in the present study. At this time, cerebral ATP is decreased far below a normal range. These results suggest that high energy phosphates such as ATP and possibly phosphocreatine of the brain are exhausted in the first five to six hours after ischaemia, and that the brain tissue becomes markedly acidotic because of an extreme production of acid metabolites such as lactic acid, pyruvic acid, and other acids. Tissue acidosis and deprivation of ATP may cause changes in cell membrane permeability, resulting in tissue oedema (Takahashi, 1966; Schmiedek et al., 1974). From our own experience (Fujishima, Ogata, and Omae, unpublished data), a significant increase in water content of the supra- 
tentorial tissue of the brain five hours after bilateral ligation in SHR, but not at one hour, may suggest that brain oedema develops in the first five to six hours after an ischaemic event in SHR. Ischaemic brain oedema may cause an additional reduction of cerebral perfusion and result in death at this time. When cerebral lactate increases to a less extent or brain oedema is less marked, the animals can survive for a longer period of time. In SHR which survived for two to three days after ligation, however, brain lactate as well as $L / P$ ratio remained increased in some rats, although cerebral ATP in these rats did not decrease. Salford and Siesjö (1974) showed that in anoxic-ischaemic rat brain there is a clear linear relationship between an increase in lactate and a decrease in adenylate energy charge at lactate levels exceeding $25 \mathrm{mmol} / \mathrm{kg}$.

Immediately after inducing anoxic-ischaemic damage to the rat brain, Spector (1965) reported that cerebral lactate increased by four times the control and remained elevated during the following 24 hours. In these rats, a concomitant decrease in cerebral ATP was accompanied by decreases in ADP and AMP, suggesting that the biochemical event during anoxic ischaemia is a failure of oxidative phosphorylation and also inhibition in the synthesis of ADP and AMP. In contrast with this observation, Salford et al. (1973) showed in rats with Levine's procedure that brain lactate and $\mathrm{L} / \mathrm{P}$ ratio were pronouncedly increased with a simultaneous decrease in ATP, but not in ADP or AMP, both of which increased after an anoxic-ischaemic event. A prolonged production of excess lactic acid in brain tissue with consequent tissue acidosis and deprivation of ATP can lead to cell lysis and thus maintain enzyme loss (Freide, 1962; Schmiedek et al., 1974). These might cause derangement of cellular ionic balance and enzyme synthesis with resultant cerebral oedema and enzyme deficiency.

A higher mortality and a greater increase in cerebral lactate and $L / P$ ratio in SHR than in NTR after bilateral carotid ligation are compatible with the pathological changes of the brain being diffuse and severe in SHR but circumscribed and small in NTR (Ogata et al., 1976). The differences of metabolic and pathological alterations between SHR and NTR, although these animals are of the same strain, might be attributed to the haemodynamic difference rather than the morphological one. Ligation of both carotid arteries readily reduces cerebral perfusion pressure to a greater extent in SHR than in NTR (Fujishima et al., 1975b). On the other hand, the lower blood pressure limit of cerebral autoregulation seems to be higher in SHR than in NTR, as demonstrated in severely hypertensive patients by Strandgaard et al. (1973), resulting in a greater reduction of cerebral blood flow in SHR than in NTR.

Hypertension is undoubtedly one of the major risk factors in cerebral infarction (Low-Beer and Phear, 1961; Kannel et al., 1970), and the occurrence of severe vascular changes secondary to hypertension might be operative in cerebrovascular diseases. The present study, however, may suggest that haemodynamic derangement is also an important factor in SHR for the development of cerebral infarction.

\section{REFERENCES}

Freide, R. L. (1962). An enzyme histochemical study of cerebral arteriosclerosis. Acta Neuropathologica, 2, 58-72.

Fujishima, M., Sugi, T., Morotomi, Y., and Omae, T. (1975a). Effects of bilateral carotid artery ligation on brain lactate and pyruvate concentrations in normotensive and spontaneously hypertensive rats. Stroke, 6, 62-66.

Fujishima, M., Ogata, J., Morotomi, Y., and Omae, T. (1975b). Effects of bilateral carotid artery ligation on brain metabolism in spontaneously hypertensive and normotensive rats. Japanese Heart Journal, 16, 316-318.

Harrison, M. J. G., Brownbill, D., Lewis, P. D., and Russell, R. W. R. (1973). Cerebral edema following carotid artery ligation in the gerbil. Archives of Neurology (Chic.), 28, 389-392.

Harrison, M. J. G., and Russell, R. W. R. (1972). Effect of dexamethasone on experimental cerebral infarction in the gerbil. Journal of Neurology, Neurosurgery, and Psychiatry, 35, 520-521.

Kahn, K. (1972). The natural course of experimental cerebral infarction in the gerbil. Neurology (Minneap.), 22, 510-515.

Kannel, W. G., Wolf, P. A., Vetet, J., and McNamara, P. M. (1970). Epidemiologic assessment of the role of blood pressure in stroke: the Framingham study. Journal of the American Medical Association, 214, 301-310.

Levine, S. (1960). Anoxic-ischemic encephalopathy in rats. American Journal of Pathology, 36, 1-17.

Levine, S., and Payan, H. (1966). Effects of ischemia and other procedures on the brain and retina of the gerbil (Meriones unguiculatus). Experimental Neurology, 16, 255-262.

Levine, S., and Sohn, D. (1969). Cerebral ischemia in infant and adult gerbils. Relation to incomplete circle of Willis. Archives of Pathology, 87, 315-317.

Levy, D. E., and Brierley, J. B. (1974). Communications between vertebro-basilar and carotid circulations in the gerbil. Experimental Neurology, 45, 503-508. 
Low-Beer, T., and Phear, D. (1961). Cerebral infarction and hypertension. Lancet, 1, 1303-1305.

Ogata, J., Fujishima, M., Morotomi, Y., and Omae, T. (1976). Neuropathological alterations following bilateral carotid artery ligation in normotensive and spontaneously hypertensive rats. Stroke, 7.

Okamoto, K., and Aoki, K. (1963). Development of a strain of spontaneously hypertensive rats. Japanese Circulation Journal, 27, 282-293.

Payan, H. M., Leveine, S., and Strevel, R. (1965). Effects of cerebral ischaemia in various strains of rats. Proceedings of the Society for Experimental Biology and Medicine, 120, 208-209.

Plum, F., Posner, J. B., and Alvord, E. C., Jr (1963). Edema and necrosis in experimental cerebral infarction. Archives of Neurology (Chic.), 9, 563-570.

Salford, L. G., Plum, F., and Siesjö, B. K. (1973). Graded hypoxia-oligemia in rat brain. 1. Biochemical alterations and their implications. Archives of Neurology (Chic.), 29, 227-233.
Salford, L. G., and Siesjö, B. K. (1974). The influence of arterial hypoxia and unilateral carotid artery occlusion upon regional blood flow and metabolism in the rat brain. Acta Physiologica Scandinavica, 92, 130-141.

Schmiedek, P., Baethmann, A., Sippel, G., Oettinger, W., Enzenback, R., Marguth, F., and Brendel, W. (1974). Energy state and glycolysis in human cerebral edema. The application of a new freeze-stop technique. Journal of Neurosurgery, 40, 351-364.

Spector, R. G. (1965). Content of lactic acid and adenosine mono-, di-, and triphosphates in anoxic-ischaemic rat brain. Journal of Pathology and Bacteriology, 90, 533-541.

Strandgaard, S., Olesen, J., Skinhøj, E., and Lassen, N. A (1973). Autoregulation of brain circulation in severe arterial hypertension. British Medical Journal, 1, 507-510.

Takahashi, K. (1966). Relationship between acidity and swelling in the brain. Tohoku Journal of Experimental Medicine, 90, 261-268. 